\title{
Front Matter: Volume 7089
}

, "Front Matter: Volume 7089," Proc. SPIE 7089, Remote Sensing of Fire: Science and Application, 708901 (17 September 2008); doi: 10.1117/12.806328

SPIE Event: Optical Engineering + Applications, 2008, San Diego, California, United SPIE. States 


\title{
PROCEEDINGS OF SPIE
}

\section{Remote Sensing of Fire: Science and Application}

\author{
Wei Min Hao
}

Editor

10 August 2008

San Diego, California, USA

Sponsored and Published by

SPIE 
The papers included in this volume were part of the technical conference cited on the cover and title page. Papers were selected and subject to review by the editors and conference program committee. Some conference presentations may not be available for publication. The papers published in these proceedings reflect the work and thoughts of the authors and are published herein as submitted. The publisher is not responsible for the validity of the information or for any outcomes resulting from reliance thereon.

Please use the following format to cite material from this book:

Author(s), "Title of Paper," in Remote Sensing of Fire: Science and Application, edited by Wei Min Hao, Proceedings of SPIE Vol. 7089 (SPIE, Bellingham, WA, 2008) Article CID Number.

ISSN 0277-786X

ISBN 9780819473097

Published by

SPIE

P.O. Box 10, Bellingham, Washington 98227-0010 USA

Telephone +1 3606763290 (Pacific Time) · Fax +1 3606471445

SPIE.org

Copyright (C 2008, Society of Photo-Optical Instrumentation Engineers

Copying of material in this book for internal or personal use, or for the internal or personal use of specific clients, beyond the fair use provisions granted by the U.S. Copyright Law is authorized by SPIE subject to payment of copying fees. The Transactional Reporting Service base fee for this volume is $\$ 18.00$ per article (or portion thereof), which should be paid directly to the Copyright Clearance Center (CCC), 222 Rosewood Drive, Danvers, MA 01923. Payment may also be made electronically through CCC Online at copyright.com. Other copying for republication, resale, advertising or promotion, or any form of systematic or multiple reproduction of any material in this book is prohibited except with permission in writing from the publisher. The CCC fee code is $0277-786 \mathrm{X} / 08 / \$ 18.00$.

Printed in the United States of America.

Publication of record for individual papers is online in the SPIE Digital Library.

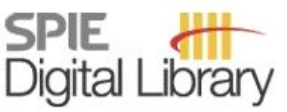

SPIEDigitallibrary.org

Paper Numbering: Proceedings of SPIE follow an e-First publication model, with papers published first online and then in print and on CD-ROM. Papers are published as they are submitted and meet publication criteria. A unique, consistent, permanent citation identifier (CID) number is assigned to each article at the time of the first publication. Utilization of CIDs allows articles to be fully citable as soon they are published online, and connects the same identifier to all online, print, and electronic versions of the publication. SPIE uses a six-digit CID article numbering system in which:

- The first four digits correspond to the SPIE volume number.

- The last two digits indicate publication order within the volume using a Base 36 numbering system employing both numerals and letters. These two-number sets start with 00, 01, 02, 03, 04, 05, $06,07,08,09,0 A, 0 B \ldots 0 Z$, followed by $10-12,20-2 Z$, etc.

The CID number appears on each page of the manuscript. The complete citation is used on the first page, and an abbreviated version on subsequent pages. Numbers in the index correspond to the last two digits of the six-digit CID number. 


\section{Contents}

$\checkmark$ Conference Committee

vii Measurement science for climate remote sensing (Plenary Paper) [7081-53]

G. T. Fraser, S. W. Brown, R. U. Datla, B. C. Johnson, K. R. Lykke, J. P. Rice, National Institute of Standards and Technology (United States)

\section{SESSION 1 KEYNOTE SESSION}

708903 Satellite remote sensing of atmospheric pollution: the far-reaching impact of burning in southern Africa (Invited Paper) [7089-01]

J. Fishman, J. A. Al-Saadi, D. O. Neil, J. K. Creilson, K. Severance, L. W. Thomason, NASA Langley Research Ctr. (United States); D. R. Edwards, National Center for Atmospheric

Research (United States)

\section{SESSION 2 GROUND OBSERVATIONS OF FIRES AND SMOKE}

708904 Acoustic and thermal characterization of a forest fire event [7089-03]

D. X. Viegas, L. P. Pita, Association for the Development of Industrial Aerodynamics (Portugal); F. Nielsen, K. Haddad, Brüel \& Kjaer Sound \& Vibration (Denmark);

C. Calisti Tassini, G. D'Altrui, D'Appolonia S.p.A. (Italy); V. Quaranta, I. Dimino, Italian Aerospace Research Ctr. (Italy)

708905 New possibilities for remote analysis of biomass burning: plumes by DOAS [7089-04]

U. Platt, Univ of Heidelberg (Germany)

\section{SESSION 3 SMOKE PLUME DYNAMICS}

708906 Investigation of optical characteristics and smoke plume dynamics in the wildfire vicinity with lidar [7089-05]

V. Kovalev, W. M. Hao, C. Wold, Forest Service, U.S. Department of Agriculture (United States); J. Newton, Sunburst Sensors, LLC (United States); D. J. Latham, Six Mile Systems (United States); A. Petkov, Forest Service, U.S. Department of Agriculture (United States)

708908 Quantitative studies of wildfire smoke injection heights with the Terra Multi-angle Imaging SpectroRadiometer [7089-07]

D. J. Diner, D. L. Nelson, Y. Chen, Jet Propulsion Lab. (United States); R. A. Kahn, NASA Goddard Space Flight Ctr. (United States); J. Logan, Harvard Univ. (United States); F.-Y. Leung, Washington State Univ. (United States); M. Val Martin, Harvard Univ. (United States) 
708909 Example applications of the MISR INteractive eXplorer (MINX) software tool to wildfire smoke plume analyses [7089-08]

D. L. Nelson, Raytheon Co. (United States); Y. Chen, Jet Propulsion Lab. (United States);

R. A. Kahn, NASA Goddard Space Flight Ctr. (United States); D. J. Diner, Jet Propulsion Lab. (United States); D. Mazzoni, Google (United States)

\section{SESSION 4 FIRE DETECTION, BURNED AREAS, AND EMISSIONS}

7089 OA Use of multiple satellite sensors in NOAA's operational near real-time fire and smoke detection and characterization program [7089-19]

M. Ruminski, J. Simko, J. Kibler, S. Kondragunta, NOAA/NESDIS (United States); R. Draxler, NOAA/ARL (United States); P. Davidson, NOAA/NWS (United States); P. Li, Perot Systems (United States)

7089 OD Vegetation burned areas derived from multiple satellite-based active fires [7089-11]

$X$. Zhang, Earth Resources Technology, Inc. at NOAA/NESDIS (United States);

S. Kondragunta, NOAA/NESDIS (United States)

7089 OF The impact of satellite-derived biomass burning emission estimates on air quality [7089-13] G. Pouliot, T. Pierce, U.S. Environmental Protection Agency (United States); X. Zhang, Earth Resources Technology, Inc. at NOAA/NESDIS (United States); S. Kondragunta, NOAA/NESDIS (United States); C. Wiedinmyer, National Ctr. of Atmospheric Research (United States); T. Pace, D. Mobley, U.S. Environmental Protection Agency (United States)

\section{SESSION 5 LONG-RANGE TRANSPORT OF SMOKE PLUMES}

7089 OG Validation of a MODIS direct broadcast burned area mapping algorithm for estimating biomass burning emissions [7089-14]

S. P. Urbanski, B. Nordgren, W. M. Hao, U.S. Forest Service (United States)

7089 Ol Relationship between ATSR fire counts and CO vertical column densities retrieved from SCIAMACHY onboard ENVISAT [7089-16]

C. Liu, M. Penning de Vries, S. Beirle, P. Hoor, T. Marbach, MPI for Chemistry (Germany); C. Frankenberg, SRON, Netherlands Institute for Space Research (Netherlands); U. Platt, Univ. of Heidelberg (Germany); T. Wagner, MPI for Chemistry (Germany)

7089 0J Biomass burning emissions from satellite observations: synergistic use of formaldehyde ( $\mathrm{HCHO}$ ), fire counts, and surface temperature [7089-17]

T. Marbach, S. Beirle, C. Liu, Max-Planck Institut for Chemistry (Germany); U. Platt, Institut of Environmental Physics (Germany); T. Wagner, Max-Planck Institut for Chemistry (Germany)

Author Index 


\title{
Conference Committee
}

\author{
Program Track Chair \\ Allen H. L. Huang, University of Wisconsin, Madison (United States) \\ Conference Chair \\ Wei Min Hao, U.S.D.A. Forest Service (United States) \\ Program Committee \\ John P. Burrows, Universität Bremen (Germany) \\ Jack Fishman, NASA Langley Research Center (United States) \\ Ulrich Platt, Ruprecht-Karls-Universität Heidelberg (Germany) \\ Mark Ruminski, National Oceanic and Atmospheric Administration \\ (United States) \\ Martin Wooster, King's College London (United Kingdom)
}

Session Chairs

$1 \quad$ Keynote Session

Wei Min Hao, U.S.D.A. Forest Service (United States)

2 Ground Observations of Fires and Smoke

Wei Min Hao, U.S.D.A. Forest Service (United States)

3 Smoke Plume Dynamics

Shawn P. Urbanski, U.S.D.A. Forest Service (United States)

4 Fire Detection, Burned Areas, and Emissions

Wei Min Hao, U.S.D.A. Forest Service (United States)

5 Long-Range Transport of Smoke Plumes

Ulrich Platt, Ruprecht-Karls-Universität Heidelberg (Germany) 
Downloaded From: https://www.spiedigitallibrary.org/conference-proceedings-of-spie on 26 Apr 2023

Terms of Use: https://www.spiedigitallibrary.org/terms-of-use 


\title{
Measurement science for climate remote sensing
}

\author{
G. T. Fraser, S.W. Brown, R.U. Datla, B.C. Johnson, K.R. Lykke, J.P. Rice \\ Optical Technology Division, National Institute of Standards and Technology \\ Gaithersburg, MD 20899-8440
}

\begin{abstract}
The NIST role in supporting our Nation's climate research is described. The assembly of climate data records over decadal time scales requires assimilating readings from a large number of optical sensors deployed in space and on the Earth by various nations. NIST, in partnership with NASA and NOAA, develops and disseminates the calibration tools and standards to ensure that the measurements from these sensors are accurate, comparable, and tied to international standards based on the SI system of units. This effort helps to provide confidence that the small decadal changes in environmental variables attributed to climate change are not an artifact of the measurement system. Additionally, it ensures that the measurements are physics based and thus comparable to climate models.
\end{abstract}

Keywords: climate change, measurement science, metrology, remote sensing

\section{INTRODUCTION}

The Earth's climate is complex and highly variable, making it difficult to measure and model small changes that occur over decadal and longer time scales. The resulting uncertainties in measurement and modeling underlie the long-term debate over the direction, magnitude, and consequence of climate change.

Even as the consensus grows on climate change, climate monitoring will continue to be necessary to quantify regional variation; to establish the effectiveness of mitigation efforts, including possible geo-engineering solutions; ${ }^{1}$ and to address the potential for catastrophic climate change events not easily amendable to modeling. Also, climate monitoring, as demonstrated in the past, is critical for the detection and mitigation of other anthropogenic environmental problems unrelated to greenhouse gas releases, such as the depletion of the Earth's stratospheric ozone layer by chlorofluorocarbons and possible future global warming from anthropogenic heat release. ${ }^{2}$

This paper focuses on the measurement challenges associated with monitoring the Earth's climate. The discussion emphasizes the passive measurement of electromagnetic radiation, which encompasses nearly all satellite measurements used in climate research. The viewpoint for the discussion is from the field of metrology, the science of measurement.

Of particular interest here are measurements required to create environmental data records, for example, global mean surface temperature as a function of time. Such long-term measurements generally have higher accuracy requirements than short-term measurements taken to quantify a specific phenomenology related to climate for use in initializing or advancing climate models.

A short-term measurement strategy emphasizing the characterization of phenomenology in the absence of supporting long-term measurement strategy to create environmental data records leads to the requirement that climate models provide the direction and magnitude of changes in climate variables. Such short-term measurements targeting specific phenomenology often do not meet the accuracy requirements or measurement time interval for creating long-term data records to monitor and track climate change. A long-term measurement strategy relies on developing highly accurate data records for specific climate variables to establish trends. Such a strategy requires sustaining high-quality measurements over decadal time scales to ascertain trends.

The need to have "immediate" answers to climate questions has led to efforts to use data records from instruments initially intended for weather forecasting and other applications having less stringent measurement uncertainty requirements than climate. An example of such an effort is the application of microwave sounding measurements from National Oceanic and Atmospheric Administration (NOAA) polar-orbiting weather satellites to detect trends in atmospheric temperature for comparison against climate modeling predictions. ${ }^{3}$ The retrospective analysis of such inherently "lower" quality measurements to improve their quality necessarily leads to increased subjectivity in the 
analysis. Such an analysis is subject to present expectations for the magnitude and direction of change in the climate variable of interest which has the potential to bias the analysis. The continued debate over the microwave sounding measurements illustrates the inherent controversy in this approach., ${ }^{4}$ Only top-of-the-atmosphere solar irradiance has had a long-term satellite effort for monitoring that approaches the level of accuracy required for climate research. ${ }^{6}$

\section{CLIMATE MEASUREMENT REQUIREMENTS}

Although the potential for climate change first came to the forefront from evidence of increasing atmospheric carbon dioxide obtained from chemical measurements on air samples acquired on Mauna Loa, Hawaii, ${ }^{7}$ at a fundamental physics level, monitoring the Earth's climate reduces to a problem in the measurement of electromagnetic radiation. As illustrated in Figure 1, at equilibrium, the incoming solar radiation, $\pi R_{\text {Earth }}{ }^{2} S_{\text {Earth }}$, balances the reflected solar radiation, $\pi R_{\text {Earth }}{ }^{2} \rho_{\text {Earth }} S_{\text {Earth }}$, and the emitted thermal infrared radiation, $4 \pi R_{\text {Earth }}{ }^{2} \sigma \varepsilon_{\text {Earth }} T_{\text {Earth }}{ }^{4}$. Any long-term change in the solar constant, $\left(S_{\text {Earth }}\right)$, in the Earth's globally averaged reflectivity (i.e., albedo) $\left(\rho_{\text {Earth }}\right)$, or in the Earth's globally averaged emissivity $\left(\varepsilon_{\text {Earth }}\right)$ will lead to a change in the Earth's globally averaged temperature, $T_{\text {Earth }}$, with the rate of change dependent on an effective time constant which encompasses a variety of phenomena such as vertical thermal transport within the oceans.

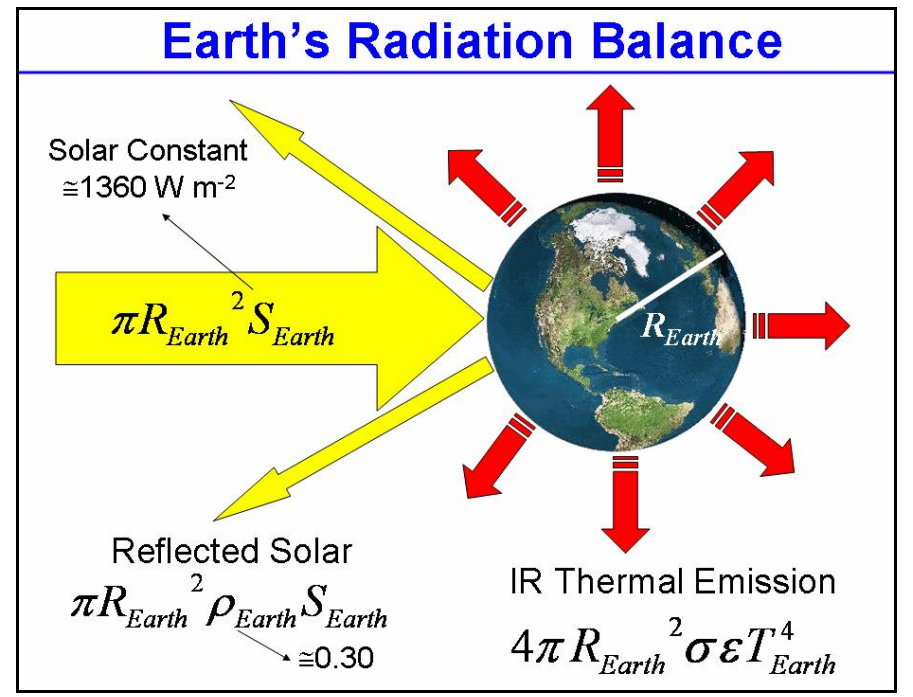

Fig. 1. A simple picture for the Earth's radiation balance. Here, $\rho_{\text {Earth }}$ is the albedo of the Earth, $\sigma$ is the Stefan-Boltzmann constant, $T_{\text {Earth }}$ is the global mean temperature of the Earth, $R_{\text {Earth }}$ is the radius of the Earth, $S_{\text {Earth }}$ is the solar irradiance at the top of the atmosphere, IR is infrared, and $\varepsilon_{\text {Earth }}$ is the global mean emissivity of the Earth.

The sensitivity of the Earth's temperature to small changes in $S_{\text {Earth }}, \rho_{\text {Earth }}$, and $\varepsilon_{\text {Earth }}$ provides estimates for the measurement accuracy requirements for these three parameters for their use in climate research. Changes in $S_{\text {Earth }}$ are natural in origin, whereas changes in $\rho_{\text {Earth }}$, and $\varepsilon_{\text {Earth }}$ have anthropogenic contributions; greenhouse gases and black aerosols for $\varepsilon_{\text {Earth }}$, and sulfate aerosols and changes in land use for $\rho_{\text {Earth }}$.

As an example, consider the changes in solar irradiance, globally averaged albedo, and globally averaged emissivity required to cause an increase in the Earth's mean temperature of $1 \mathrm{~K} / 100 \mathrm{yrs}$ or $0.01 \mathrm{~K} / \mathrm{yr}$, approximately the current rate of global warming over the last century. A $0.01 \mathrm{~K} / \mathrm{yr}$ increase in global mean temperature corresponds to a $0.19 \mathrm{Wm}^{-2} / \mathrm{yr}$ $(0.014 \% / y r)$ increase in solar irradiance, a $0.033 \% / y r$ decrease in albedo, or a $0.015 \% / y r$ decrease in emissivity.

These numbers can be compared with the uncertainties in radiometric standards disseminated by NIST which generally fail to meet the stringent requirements for climate monitoring by an order of magnitude or more:

- Spectral irradiance lamp standards for the wavelength range of $250 \mathrm{~nm}$ to $2400 \mathrm{~nm}$ have uncertainties of $0.3 \%$ to $1.6 \%(k=2$ or $2 \sigma)$, depending on wavelength.

- Pressed and sintered polytetrafluoroethylene (PTFE) reflectance standards for near-normal incident directional hemispherical reflectance have uncertainties varying from $0.67 \%$ at $200 \mathrm{~nm}$ to $0.21 \%$ at $1600 \mathrm{~nm}$. 
- Spectral emissivity standards from $1 \mu \mathrm{m}$ to $14 \mu \mathrm{m}$ have uncertainties of approximately $1 \%$ for a Lambertian material with $\varepsilon \cong 0.6$.

Programs needing lower uncertainties must work directly with NIST to have direct access to laboratory calibration tools such as the Primary Optical Watt Radiometer (POWR) and the Facility for Spectral Irradiance and Radiance Responsivity Calibrations using Uniform Sources (SIRCUS) discussed below, however, even these capabilities are generally not sufficient to enable remote-sensing instruments to achieve the low uncertainties required for detecting and monitoring small changes in the Earth's radiation balance expected with climate change.

Measuring small changes in radiometric sources at the level of uncertainty required for climate monitoring is extremely challenging, be it the Earth, Sun, or a laboratory source or artifact. That no validated satellite remote-sensing instrument has achieved the uncertainty requirements for monitoring any of the three components (solar, reflected solar, or emitted infrared) of the Earth's radiative balance attests to the challenge. Moreover, the measurement uncertainties for climate quoted above are even more stringent (by approximately a factor of 3 ignoring correlation) if a combination of changes in solar irradiance, albedo, and emissivity are considered. In realization of this measurement challenge scientists have resorted to the tracking of secondary environmental variables, such as sea-ice extent in the Artic, which are more sensitive to climate change but also more difficult to include in climate models.

Adding to the measurement challenge is that changes in the Earth's climate system must be detected against the larger natural fluctuations that arise from day-to-day weather variations, the seasons, the eleven-year solar cycle, and major cyclical climate phenomena such as El Niño and La Niña. Despite such fluctuations, the reliability of climate trending from environmental data records continues to benefit from reductions in measurement uncertainty. ${ }^{8}$

Further details on measurement requirements for climate are provided in the report of a 2002 workshop cosponsored by NIST, NASA, NOAA, and NPOESS/NPP (National Polar-orbiting Operational Environmental Satellite System/NPOESS Preparatory Project. The report emphasizes satellite-based measurements. ${ }^{9}$ A follow-on report recently released addresses strategies to reach these requirements. ${ }^{10}$

\section{NEED FOR TRACEABILITY TO SI STANDARDS WITH LOW UNCERTAINTIES TO MEET CLIMATE REQUIREMENTS}

The ability to unambiguously detect and accurately quantify small yearly changes in the Earth's climate over decadal and longer time scales requires that the measurements be tied, i.e., traceable, to international standards based on the International System of Units, the SI, as maintained by national metrology institutes such as NIST. This viewpoint has been articulated in the Strategic Plan for the U.S. Climate Change Program ${ }^{11}$ and in an agreement ${ }^{12}$ between the World Meteorology Organization (WMO), representing national weather services, and the International Committee for Weights and Measures (CIPM), representing national measurement laboratories.

SI traceability has several advantages for climate research. It ensures that the measurements are based on the fundamental laws of physics and thus can be compared with predictions from physics-based modeling. Physics-based modeling is critical for developing climate models that are objective and have the flexibility to advance as the state of knowledge of climate physics improves and computational capabilities increase.

SI traceability also allows measurements to be compared independent of time or of the organization or country performing the measurements. Measurement comparability is essential for the success of international efforts dependent on exchange and integration of measurements, such as the Global Earth Observation System of Systems (GEOSS). ${ }^{13}$

Except for the kilogram, the ability to realize a standard for an SI unit does not require access to a specific artifact. Thus, SI-based standards can be and are realized and disseminated by NIST and other National Measurement Institutes (NMIs) around the world without access to specific artifacts. The standards and any changes in the standards are well documented by the NMIs, providing the necessary information to tie past and future realizations of the SI units with present realizations. Additionally, the NMIs validate and document the quality of their SI standards through measurement comparisons held under the auspices of the International Committee for Weights and Measures formed by the Treaty of the Meter. The results from such comparisons are made available on the website of the Bureau of Weights and Measures (BIPM). ${ }^{14}$ 
The results from one such measurement comparison relevant to climate research is shown in Figure $2 .{ }^{15}$ The Figure illustrates the level of agreement with respect to a reference value for measurements of the spectral irradiance of $1 \mathrm{~kW}$ FEL-type quartz-tungsten-halogen lamps by 12 participating national metrology institutes, including NIST.

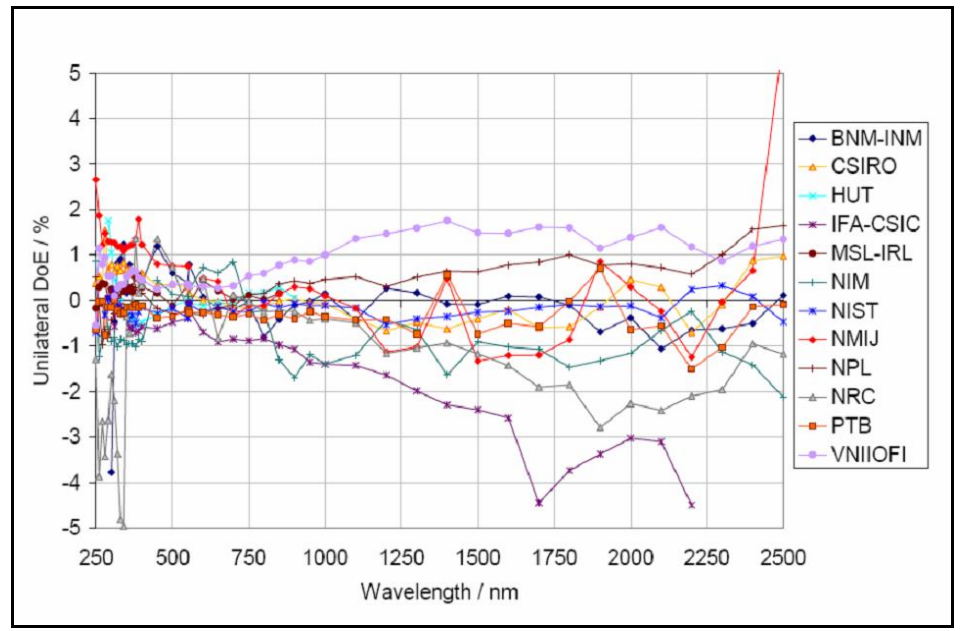

Fig. 2. Results from an international comparison of spectral irradiance measurements between National Metrology Laboratories (NMIs). Measurements are given as a percent difference relative to a reference value. The acronyms reference the twelve participating NMIs and are defined at http://www.bipm.org/en/practical info/acronyms.html.

These lamps are typically used by remote-sensing scientists to realize a spectral radiance scale by illuminating a nearperfect Lambertian reflector consisting of pressed and sintered polytetrafluoroethylene. The measurement mimics in the laboratory the illumination of the Earth by the Sun, although the color temperature of the lamp of $2950 \mathrm{~K}$ is approximately a factor of two smaller than the approximately $5900 \mathrm{~K}$ radiance temperature of the Sun as measured at the top of the atmosphere. This discrepancy between the spectral outputs of the FEL lamp and the Sun needs to be addressed in calibrating instruments monitoring direct or reflected solar radiation to reduce spectrally dependent stray light errors. Note that the typical agreement of approximately $1 \%$ in the intercomparison is approximately two orders of magnitude larger that the uncertainty requirement for long-term monitoring of the total solar irradiance of the Sun.

\section{NIST INFRARED-TO-ULTRAVIOLET SI RADIATION STANDARDS}

NIST standards for the measurement of electromagnetic radiation from the infrared to the ultraviolet are tied to the watt, kelvin, and meter. An extensive infrastructure has been developed to ensure the ability of NIST to provide the lowest uncertainty standards for various applications in industry, defense, and environment. Climate research, in particular, requires standards with extremely low uncertainty to meet the stringent measurement requirements discussed above. The low uncertainty requirements for climate have provided the greatest drive for reducing the uncertainties in NIST's fundamental and disseminated electromagnetic radiation standards.

The Primary Optical Watt Radiometer (POWR) is the NIST developed and maintained National standard for measurement of optical power. ${ }^{16}$ POWR shown in Figure 3 is a liquid-helium-cooled cryogenic radiometer which compares the optical power from a laser beam incident on a high-absorptivity optical cavity with the electrical power dissipated by a resistor in thermal contact with the cavity, thus tying the optical watt to the electrical watt. The laser beam of known optical power determined to an expanded relative uncertainty $k=2$ of $0.02 \%$ as verified through international comparisons among NMIs is used to calibrate extremely linear, high-dynamic-range silicon trap detectors for measurement of the radiance $\left[\mathrm{W} \mathrm{m}^{-2} \mathrm{sr}^{-1}\right]$ or irradiance $\left[\mathrm{W} \mathrm{m}^{-2}\right]$ of integrating sphere sources used to calibrate remote sensing instruments. Trap detectors typically have a circular optical aperture of accurately known area with diameter larger than the laser beam diameter to realize an absolute irradiance responsibility standard, or absolute spectral irradiance responsivity standard if the laser wavelength is varied in the transfer of the calibration from POWR to the trap detector.

To measure the area of the apertures used in the realization of an irradiance or radiance standard a coordinate measurement machine (CMM) is used. The CMM uses an optical microscope to map the coordinates of the edges of the aperture as it is moved through the focus of the microscope. ${ }^{17}$ The relative position of the $x-y$ translation stage used in 
the mapping of the aperture is measured interferometrically by referencing to etalon fringes generated from a frequency stabilized HeNe. The laser interferometry ties the aperture area determination to the meter through the accurately known wavelength of the HeNe laser. The resulting aperture-area measurements have uncertainties of less than $0.01 \% k=2$. The uncertainties have been validated through international comparisons which also revealed significant discrepancies below the $0.01 \%$ level between aperture measurements performed using optical methods and contact methods. ${ }^{18}$

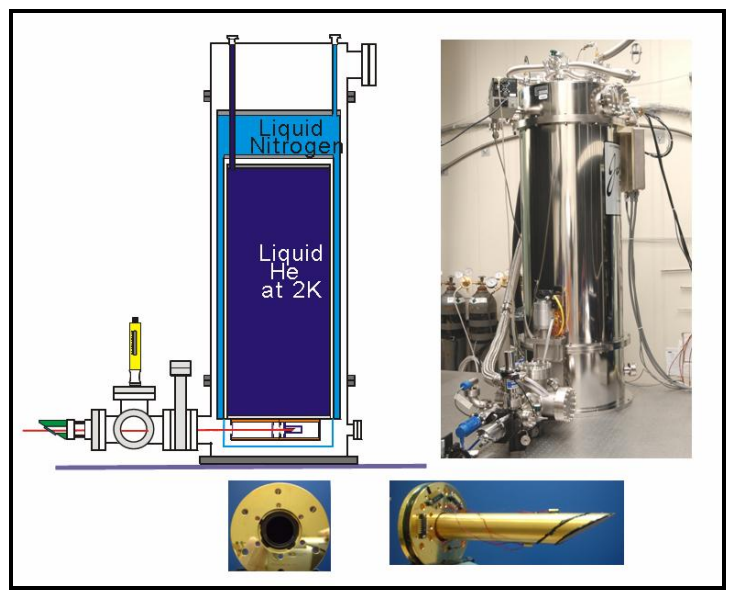

Fig. 3. A schematic diagram and picture of the NIST Primary Optical Watt Radiometer (POWR), the Nation's primary standard for optical power. POWR is a cryogenic radiometer which compares optical power to electric power to tie the optical watt to the electrical watt. POWR can determine the optical power in a laser beam to $0.02 \% k=2$.

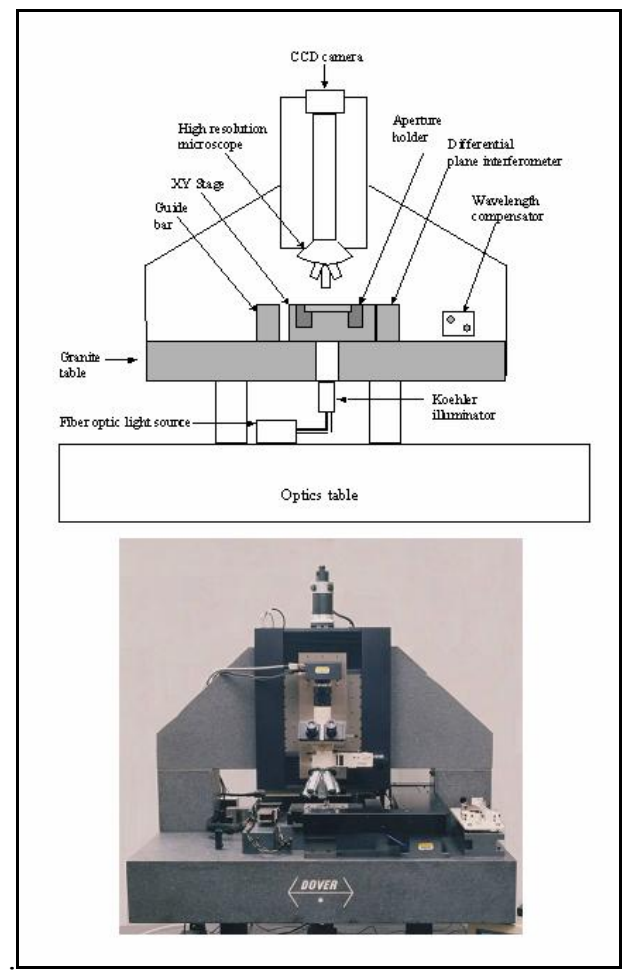

Fig. 4. A schematic diagram and picture of the NIST Absolute Aperture Area Measurement Facility. The facility uses an optical microscope to view the edge points of an optical aperture as it is moved through the focus of the microscope on an interferometrically controlled $\mathrm{x}-\mathrm{y}$ translation stage. The area of an aperture is determined to better than $0.01 \%(k=$ 2). 
Use of apertures in irradiance or radiance standards requires correction for diffraction effects, particularly for long wavelengths and small apertures, or when the measurement requirements are particularly stringent. NIST has developed sophisticated models to correct for diffraction effects in radiometry. Diffraction corrections have played a critical role in a number of applications, including satellite measurements of solar irradiance, ${ }^{19}$ infrared photometric measurements of stars, ${ }^{20}$ and infrared measurements of blackbodies in low-thermal-background space vacuum chambers used in testing sensors for ballistic missile defense. ${ }^{21}$

To transfer the radiometric scales achieved above to various sensors used in climate research, NIST has developed a unique laser-based facility called SIRCUS for Spectral Irradiance and Radiance Responsivity Calibrations using Uniform Sources. ${ }^{22}$ SIRCUS uses a set of wavelength-tunable lasers from the infrared to the ultraviolet fiber-coupled to the interior of an integrating sphere with an exit port to provide a source of known radiance or irradiance as defined through an appropriate set of apertures and referenced absolutely using a trap detector. SIRCUS allows the absolute calibration of optical radiation sensors to approximately $0.05 \%$ in spectral responsivity provided that the sensor is sufficiently stable to hold the calibration through the time it is used. Additionally, SIRCUS provides an end-to-end system level calibration of the sensor under real illumination conditions that fully fill the entrance pupil to the sensor.

At longer wavelengths, i.e., in the thermal infrared, NIST's room-temperature-background radiometric scales are based on high-emissivity blackbody sources with radiance levels tied to the kelvin through contact thermometry. One such blackbody is the so-called NIST Water Bath Blackbody (WBBB) based on a black-painted $10.8 \mathrm{~cm}$ diameter, $25 \mathrm{~cm}$ deep, conical optical cavity immersed in a reservoir of water whose temperature is variable over the range $15{ }^{\circ} \mathrm{C}$ to 80 ${ }^{\circ} \mathrm{C}$ and measured using accurate platinum resistance thermometers. The WBBB was used to validate the radiometric scales of several programs involved in the measurement of sea-surface temperature (SST). ${ }^{23}$

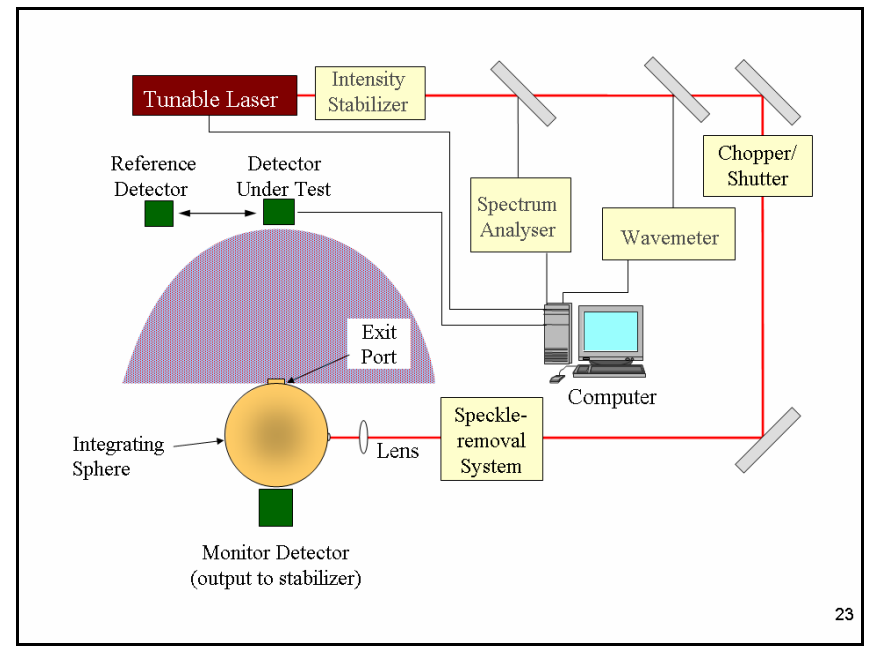

Fig. 5. A schematic diagram and picture of the NIST Facility for Spectral Irradiance and Radiance Responsivity Calibrations using Uniform Sources (SIRCUS). SIRCUS uses a suite of lasers from the short wavelength infrared (SWIR) to the ultraviolet (UV) to illuminate an integrating sphere source to produce a uniform radiance source of known absolute intensity as determined using standard trap detectors calibrated against a cryogenic radiometer such as POWR.

\section{EXTENDING TRACEABILITY WITH LOW UNCERTAINTES TO CLIMATE MEASUREMENTS-PRELAUNCH CALIBRATION}

Satellite programs generally have requirements that the prelaunch radiometric calibration be tied to international standards based on the SI system of units. One of the twenty Global Climate Observing System (GCOS) Climate Monitoring Principles ${ }^{24}$ affirm this goal by stating, "Rigorous pre-launch instrument characterization and calibration, including radiance confirmation against an international radiance scale provided by a national metrology institute, should be ensured." Ground-based measurements likewise need such traceability to help validate and calibrate satellite measurements and ensure comparability with satellite measurements when integrated into climate data records. In response to these needs NIST has developed a variety of standards, calibration tools, and training resources to help establish the traceability of climate measurements to the SI system of units. 
For near-infrared to ultraviolet radiation standards, NIST provides calibration services for spectral radiance standards based on lamp-illuminated integrating spheres, spectral reflectance standards based on polytetrafluoroethylene, and spectral-irradiance standards based on FEL lamps. The latter two standards when used together provide a spectral radiance standard. The polytetrafluoroethylene plaque is illuminated at normal incidence with a known spectral irradiance level from the FEL lamp producing a spectral radiance standard when viewed, typically at $45^{\circ}$ off normal as the plaque reflectance is usually measured for this so-called $0^{\circ} / 45^{\circ}$ geometry. A typical user of integrating sphere and lamp-plaque radiance standards achieves agreement with the NIST radiance scale to approximately $2 \%$, as demonstrated by a recent spectral radiance scale intercomparison between 10 laboratories involved in ocean color research. ${ }^{25}$ Similarly, a $2 \%$ agreement is also seen when comparing bidirectional reflectance distribution function (BRDF) measurements on polytetrafluoroethylene reflectance standards. ${ }^{26}$

In collaboration with the Earth Observing System (EOS) satellite program, NIST has developed a series of standard radiometers and radiance standards to validate the radiometric scales of the satellite programs. These radiometers have been well described in the literature and include the Thermal-infrared Transfer Radiometer (TXR), a mid-wave and longwave thermal-infrared radiometer; the six-channel filter-based Visible Transfer Radiometer (VXR); and the Short-Wave Infrared Radiometer (SWXIR). The VXR has been used to verify the visible and near-infrared radiance scales of the lamp-illuminated integrating spheres used in support of the Moderate Resolution Imaging Spectrometer (MODIS), the Multi-angle Imaging Spectrometer (MISR), and the Advanced Spaceborne Thermal Emission and Reflection Radiometer (ASTER) while the SWXIR has been used to validate the short-wave infrared radiance scale of the MODIS sphere. The TXR has supported the Multispectral Thermal Imager (MTI), ${ }^{27}$ Geostationary Operational Environmental Satellite (GOES) imager, Moderate Resolution Imaging Spectroradiometer (MODIS), and the NPOESS Visible Infrared Imaging Spectroradiometer Suite (VIIRS) and Cross-track Infrared Sounder (CRIS).

NIST has also developed a version of SIRCUS, denoted Traveling SIRCUS, designed for transportation to satellite and ground-sensor test and evaluation facilities to perform full system-level characterization and calibration of sensors operating from the near-infrared to the ultraviolet, within the reflected solar region. Traveling SIRCUS has been used to calibrate and characterize the Earth Polychromatic Imaging Camera (EPIC), the Marine Optical Buoy (MOBY), and the Robotic Lunar Observatory (ROLO), as well as several astronomical telescope systems.

\section{EXTENDING TRACEABILITY WITH LOW UNCERTAINTIES TO CLIMATE MEASUREMENTS-POST-LAUNCH CALIBRATION}

The challenge remains to verify that the prelaunch calibration is maintained on orbit. On-orbit SI traceability mitigates the risk associated with a satellite failure in the creation of long-term data records. A number of strategies have been developed to assess, maintain, and improve the quality of satellite measurements on orbit, including using so called vicarious calibration sites based on Earth targets such as deep convective clouds and desert scences, the Moon, or stars; satellite measurement comparisons; and on-board calibration.

In the event of continuous monitoring of one or more climate variables using a series of satellites, such as the NOAA geostationary and polar-orbiting satellites, data records have been generated using the strategy as outlined in Figure 6 . Here the individual measurement time series or data records are merged into one continuous record by choosing one of the satellites as the reference and using the satellite measurement temporal overlaps to align all the other satellite measurements to the reference satellite measurements. The satellite overlaps could be averaged over some portion of the overlap period, such as done with top-of-the-atmosphere solar irradiance measurements, or could be based on simultaneous measurements using actual spatial and temporal overlaps, so called Simultaneous Nadir Overlaps (SNOs) ${ }^{28}$ which occur most often in the polar regions for polar-orbiting satellites. A difficult to test assumption in generating such lengthy time series is that the satellites do not share any systematic instrument drift. This assumption may not always hold at the level required for climate research as typically satellite instruments involved in the creation of such long time series share significant hardware and calibration heritage and thus are potentially prone to common systematic drifts.

The Moon and stars are also used to provide a relative calibration of satellite sensors and to track sensor degradation. The lack of a Lunar atmosphere, the absence of significant geological activity, and constant solar exposure over billions of years provide confidence in the assumption that the surface reflectance is constant over the decadal time scales 
associated with satellite remote sensing of the Earth's climate. Using Earth-viewing sensors to view the Moon in combination with the Lunar reflectance model developed by the Robotic Lunar Observatory (ROLO ${ }^{29}$ to correct for the effect of the Moon's phase and libration on the satellite measurement has been demonstrated to be an effective approach for long-term tracking of instrument stability within a spectral channel. ${ }^{30}$ A concept has been proposed called LUSI for Lunar Spectral Irradiance ${ }^{31}$ for improving the absolute calibration of the Moon beyond the level achieved by ROLO.

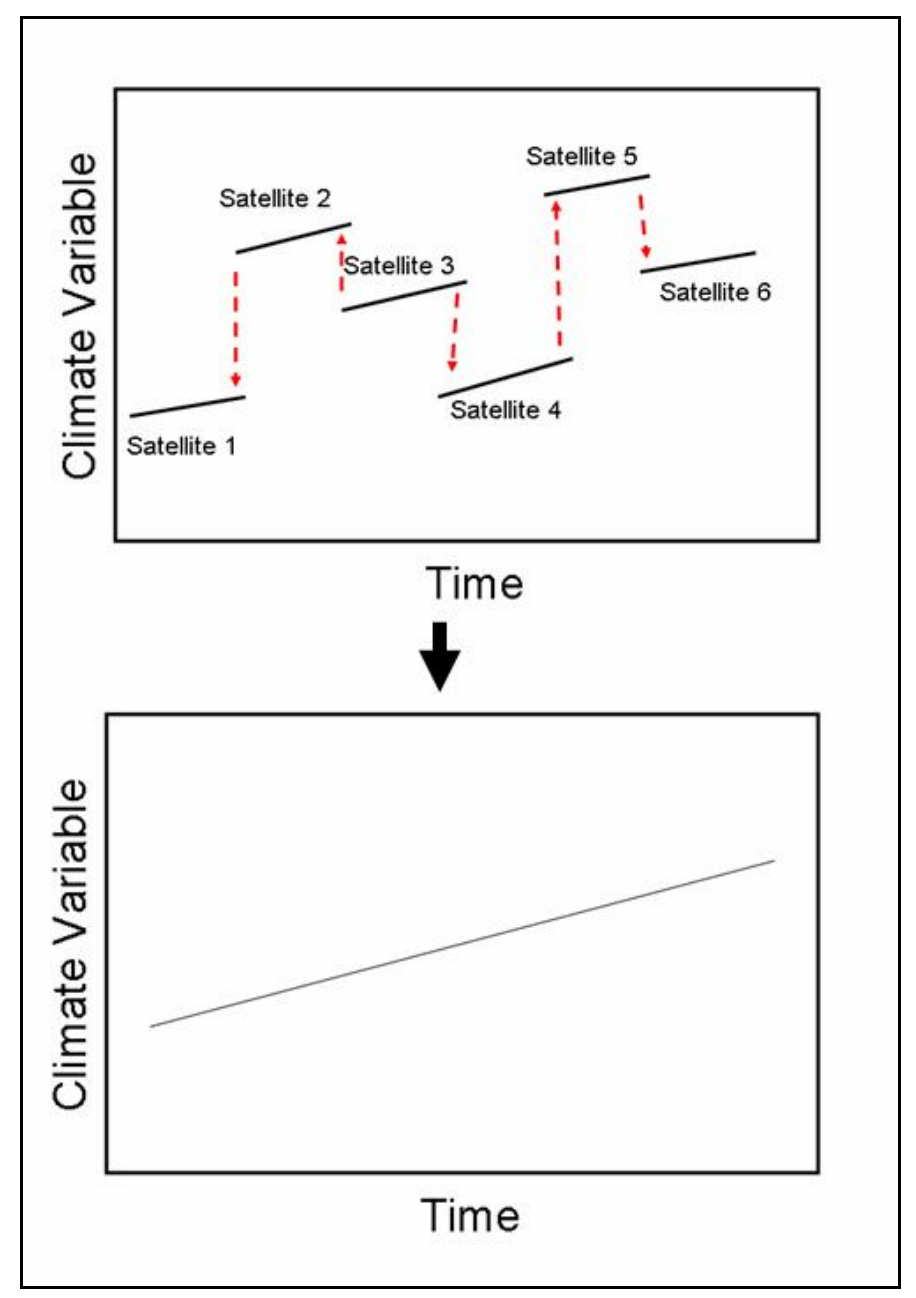

Fig. 6. The two panels demonstrate the creation of an environmental data record by stringing together a set of records from a series of satellites and shifting the individual satellite calibrations relative to one of the satellites taken as the standard or reference. This approach does not consider the possibility of shared drift among the satellites originating from their common heritage.

\section{ESTABLISHING AND VALIDATING SI TRACEABILITY IN SPACE WITH LOW UNCERTAINTIES}

One of the twenty Global Climate Observing System (GCOS) Climate Monitoring Principles states that "On-board calibration adequate for climate system observations should be ensured and associated instrument characteristics monitored." Satellite programs continue to struggle with meeting this principle even though it is less stringent than the GCOS prelaunch principle referenced above advocating for "Rigorous pre-launch instrument characterization and calibration..." On-board calibration approaches include polytetrafluoroethylene reflectance standards which degrade in reflectivity from high-energy radiation and particles ${ }^{32}$ and have suffered from stray-light contamination due to earth shine. ${ }^{33}$ 
Increased attention is being given to on-board satellite calibration. The need for improved space-based benchmark measurements of top-of-the-atmosphere spectral radiance emitted by the Earth has led to calls within the Decadal Survey ${ }^{34}$ performed by the National Research Council for a CLARREO (Climate Absolute Radiance and Refractivity Observatory) mission in which the on-board sensor calibration to the SI system of units is rigorous. In principle, such benchmark instruments with appropriate spectral and spatial corrections could be used to calibrate other satellite instruments in support of the World Meteorological Organizations (WMO) Global Space-Based Inter-Calibration System (GSICS) effort. ${ }^{35}$

\section{THE NEED FOR LOWER UNCERTAINTY SI STANDARDS}

Achieving the measurement requirements for long-term monitoring of the radiative balance of the Earth as illustrated in Figure 1 is challenging. Past and future efforts at meeting satellite measurement requirements in the context of the Earth Observing System experience have been discussed by Butler et al. ${ }^{36}$ Remote-sensing programs using NISTdisseminated standards presently achieve radiometric uncertainties approximately two orders of magnitude larger than required for quantifying the radiative balance. Moreover, the uncertainties on the standards are also too large, by about an order of magnitude relative to the measurement requirements. The measurement requirements for monitoring the Earth's radiative balance have reached the limit of what can presently be achieved from the fundamental SI radiometric standards maintained at NIST. Research advances are required in all areas of the measurement traceability chain, from the fundamental standards to the disseminated standards to the remote sensing instrument calibration and characterization, to ensure that climate monitoring requirements are met.

SIRCUS and Traveling SIRCUS tied to cryogenic radiometry as discussed above are examples of tools that allow remote sensing programs to achieve instrument calibration at lower uncertainties relative to the SI than possible with standards typically disseminated by NIST such as spectral radiance standards based on a NIST calibrated integrating sphere source. NIST is also researching other approaches, including hyperspectral image projection ${ }^{37}$, absolute pyrometry ${ }^{38}$, spectrally tunable sources $^{39}$, and stray-light correction algorithms and characterization methods, ${ }^{40}$ to improve the calibration of remote-sensing instruments tied to NIST standards. A long-term research program has also been implemented to develop alternative approaches for optical power standards based on the counting of individual photons as cryogenic radiometry has not advanced significantly over the last couple of decades beyond the $0.02 \%(k=2)$ relative uncertainty level.

\section{CONCLUSION}

The accurate monitoring of the Earth's climate from using ground and space-based sensors will continue to depend on access to the highest accuracy fundamental SI standards for the passive measurement of electromagnetic radiation from the microwave to the ultraviolet spectral regions. Such standards are developed, maintained, improved, and compared by the world's National Metrology Institutes. Traceability to the SI ensures that measurements are comparable between organizations, countries, and over generations. Such traceability when established at a uncertainty level necessary to monitor the Earth's radiation balance provides confidence in the quality of climate data records used to predict the direction and rate of climate change. Additionally, SI traceable measurements are the foundation of climate models tied to the laws of physics.

\section{ACKNOWLEDMENTS}

We would like to acknowledge our colleagues within the Optical Technology Division who have aided the effort to advance optical radiation standards to meet the demands for climate research. 


\section{REFERENCES}

[1] Such geo-engineering solutions include the controlled introduction of reflective sulfate aerosols into the upper atmosphere. See, for example, Crutzen, P. J., "Albedo Enhancement by Stratospheric Sulfur Injections," Climate Change 77, 211-220 (2006).

[2] Chaisson, E. J., "Long-Term Global Heating from Energy Usage,” EOS 89(28) (2008).

[3] Karl, T. R., Hassol, S. J., Miller, C. D., and Murray, C. D. (editors), [Temperature Trends in the Lower Atmosphere: Steps for Understanding and Reconciling Differences], A Report by the Climate Change Science Program and the Subcommittee on Global Change Research, Washington, DC (2006).

[4] See, for example, Randall, R. M. and Herman, B. M., "Using limited time period trends as a means to determine attribution of discrepancies in microwave sounding unit-derived tropospheric temperature time series," Journal of Geophysical Research-Atmospheres 113(D5) D05105 (2008), and references therein.

[5] See, for example, Zou, C. Z., Goldberg, M. D., Cheng, Z. H., Grody, N. C., Sullivan, J. T., Cao, C. Y., and Tarpley, D., "Recalibration of microwave sounding unit for climate studies using simultaneous nadir overpasses," 111(D19), D19114 (2006), and references therein.

[6] http://spot.colorado.edu/ $\mathrm{koppg} / \mathrm{TSI}$

[7] Keeling, C. D., Bacastow, R. B., Bainbridge, A. E., Ekdahl, Jr., C. A., Guenther, P. R., Waterman, L. S., and Chin, J. F. S., "Atmospheric carbon dioxide variations at Mauna Loa Observatory, Hawaii," Tellus 28, 538-551 (1976). Also see http://www.esrl.noaa.gov/gmd/ccgg/trends/.

[8] Leroy, S. S., et al., "Climate Signal Detection Times and Constraints on Climate Benchmark Accuracy Requirements," J. Climate, to be published.

[9] Ohring, G., Wielicki, B., Spencer, R., Emery, B., and Datla, R., (editors), [Satellite Instrument Calibration for Measuring Global Climate Change], Report of a Workshop Organized by National Institute of Standards and Technology (NIST), National Polar-orbiting Operational Environmental Satellite System-Integrated Program Office (NPOESS-IPO), National Oceanic and Space Administration (NOAA), National Aeronautics and Space Administration (NASA)], Workshop held at the University of Maryland Inn and Conference Center, College Park, MD, Nov. 12-14, 2002. Published as NISTIR 7047 (2004) available at http://physics.nist.gov/Divisions/Div844/publications/NISTIR7047/nistir7047.pdf.

[10] Ohring, G. (editor), [Achieving Satellite Instrument Calibration for Climate Change (ASIC3)], Report of a Workshop Organized by National Oceanic and Atmospheric Administration, National Institute of Standards and Technology, National Aeronautics and Space Administration, National Polar-orbiting Operational Environmental Satellite System-Integrated Program Office, and Space Dynamics Laboratory of Utah State University at the National Conference Center, Lansdowne, VA, May 16-18, 2006. Available at http://www.star.nesdis.noaa.gov/star/documents/ASIC3-071218-webversfinal.pdf.

[11] [Strategic Plan for the U.S. Climate Change Science Program], A Report by the Climate Change Science Program and the Subcommittee on Global Change Research (2003). Available at http://www.climatescience.gov/Library/stratplan2003/final/ccspstratplan2003-all.pdf.

[12] "WMO and CIPM agree to consult together to ensure that data, related in particular to atmospheric composition and water resources, coming from the programmes of WMO are properly based on units traceable to the International System (SI) through the procedures of the Mutual Recognition Arrangement for National 
Measurement Standards drawn up by the Committee and those of the Technical Regulations of WMO." For further details see http://www.bipm.org/utils/en/pdf/CIPM-WMO.pdf.

[13] See, for example, http://www.epa.gov/geoss/.

[14] See www.bipm.org for further information.

[15] Woolliams, E. R., Fox, N. P., Cox, M. G., Harris, P. M., and Harrison,N. J. "Final report on CCPR K1-a: Spectral irradiance from $250 \mathrm{~nm}$ to $2500 \mathrm{~nm}$," Metrologia Technical Supplement 43, 02003 (2006). Also see http://kcdb.bipm.org/appendixB/KCDB_ApB info.asp?cmp_idy=478\&cmp_cod=CCPR-K1.a\&prov=exalead.

[16] Houston, J. M. and Rice, J. P., "NIST reference cryogenic radiometer designed for versatile performance," Metrologia 43 S31-35 (2006).

[17] Fowler, J. and Litorja, M. "Geometric area measurements of circular apertures for radiometry at NIST," Metrologia 40(1), S9-S12 (2003).

[18] Litorja, M., Fowler, J., Hartmann, J., Fox, N., Stock, M., Razet, A., Khlevnoy, B., Ikonen, E., Machacs, M., and Doytchinov, K., "Final report on the CCPR-S2 supplementary comparison of area measurements of apertures for radiometry," Metrologia Technical Supplement 44, 02002 (2007).

[19] Butler, J. J., Johnson, B. C., Rice, J. P., Shirley, E. L., and Barnes, R. A., "Sources of differences in on-orbit total solar irradiance measurements and Description of a Proposed Laboratory Intercomparison," in press.

[20] Witteborn, F. C., Cohen, M., Bregman, J. D., Wooden, D. H., Heere, K., and Shirley, E. L., "Spectral irradiance calibration in the infrared. XI. Comparison of alpha Bootis and 1 Ceres with a laboratory standard," Astronomical Journal 117(5), 2552-2560 (1999).

[21] Carter, A. C., Datla, R. U., Jung, T. M., Smith, A. W., and Fedchak, J. A., "Low-background temperature calibration of infrared blackbodies," Metrologia 43 (2006) S46-S50.

[22] Brown, S. W., Eppeldauer, G. P., and Lykke, K. R., "Facility for spectral irradiance and radiance responsivity calibrations using uniform sources," Applied Optics 45(32), 8218-8237 (2006).

[23] Rice, J. P., Butler, J. J., Johnson, B. C., Minnett, P. J., Maillet, K. A., Nightingale, T. J., Hook, S. J., Abtahi, A., Donlon, C. J., and Barton, I. J., "The Miami 2001 infrared radiometer calibration and intercomparison: Part I. Laboratory characterization of blackbody sources,” J. Atmos. and Oceanic Tech. 21(2), 258-267 (2004).

[24] The Global Climate Observing System (GCOS) Climate Monitoring Principles are listed at http://www.wmo.ch/pages/prog/gcos/index.php?name=monitoringprinciples.

[25] Meister, G., Abel, P., Carder, K., Chapin, A., Clark, D., Cooper, J., Davis, C., English, D., Fargion, G., Feinholz, M., Frouin, R., Hoge, F., Korwan, D., Lazin, G., McClain, C., McLean, S., Menzies, D., Poteau, A., Robertson, J., Sherman, J., Voss, K., and Yungel, J., The Second SIMBIOS Radiometric Intercomparison (SIMRIC-2), March November 2002, NASA/TN-2002-210006, Vol. 2, Aug. 2003.

[26] Early, E. A., Barnes, P. Y., and Johnson, B. C., Butler, J. J., Bruegge, C. J., Biggar, S. F., Spyak, P. R. and Pavlov, M. M., "Bidirectional Reflectance Round-Robin in Support of the Earth Observing System Program," Journal of Atmospheric and Oceanic Technology 17(8), 1077-1091 (2000).

[27] Rice, J. P., Bender, S. C., Atkins, W. H., and Lovas, F. J., "Deployment test of the NIST EOS Thermal-infrared Transfer Radiometer," International Journal of Remote Sensing 24, 367-388 (2003). 
[28] Zou, C. -Z., Goldberg, M. D., Cheng, Z., Grody, N. C., Sullivan, J. T., Cao, C., and Tarpley, D. "Recalibration of microwave sounding unit for climate studies using simultaneous nadir overpasses," Journal of Geophysical Research 111, D19114 (2006).

[29] T. C. Stone and H. H. Kieffer, "Use of the Moon to support on-orbit sensor calibration for climate change measurements,” Proc. SPIE 6296 (2006). For additional references see http://www.moon-cal.org/index.php.

[30] Eplee, Jr., R. E., Bailey, S. W., Barnes, R. A., Kieffer, H. H., and McClain, C. R., “Comparison of SeaWiFS OnOrbit Lunar and Vicarious Calibrations," Proc. of SPIE 6296, 629610 (2006).

[31] Smith, A. W., Lorentz, S. R., Stone, T. C., Yoon, H., Datla, R. V., Pollock, D., and Tansock, J., "LUnar Spectral Irradiance and radiance (LUSI): Instrumentation to characterize the moon as an SI-traceable radiometric standard," http://www.goesr.gov/downloads/GOES\%20Users $\%$ 20Conference $\% 20 \mathrm{~V} / \mathrm{GUC} \% 20 \mathrm{~V} \% 20$ Posters $\% 202 /$ poster_Smith $\% 2021 . p d f$.

[32] Xiong, X., Erives, H., Xiong, S., Xie, X., Esposito, J., Sun, J., Barnes, W., "Performance of Terra MODIS solar diffuser and solar diffuser stability monitor," Proc. of SPIE 5882, 58820S.1 (2005).

[33] Wolfe, R. E.,Esaias, W., Lyapustin, A., Xiong, X, “MODIS solar diffuser Earthshine modeling and analysis,” Proc. of SPIE 6296, 629606 (2006).

[34] [Earth Science and Applications from Space: National Imperatives for the Next Decade and Beyond], National Research Council, The National Academies Press (2007). Available at http://www.nap.edu/catalog.php?record id=11820.

[35] For further information visit the GSICS website at http://www.star.nesdis.noaa.gov/smcd/spb/calibration/icvs/GSICS/index.html.

[36] Butler, J. J, Johnson, B. C., Rice, J. P., Brown, S. W., and Barnes, R. A., "Validation of radiometric standards for the laboratory calibration of reflected-solar Earth observing satellite instruments," Proc. of SPIE 6677, 667707 (2007).

[37] Brown, S.W., Myers, B., Barnes, R. A., Rice, J. P., "Characterization of Earth observing satellite instruments for response to spectrally and spatially variable scenes," Proc. of SPIE 6677, 667705 (2007).

[38] Allen, D. W., Saunders, R. D., Johnson, B. C., Gibson, C. E., and Yoon, H. W., "The Development and Characterization of an Absolute Pyrometer Calibrated for Radiance Responsivity," AIP Conference Proceedings 684, 577 (2003).

[39] Fryc, I., Brown, S. W., Eppeldauer, G. P., and Ohno, Y., "LED-based spectrally tunable source for radiometric, photometric, and colorimetric applications," Optical Engineering 44(11), 111309 (2005).

[40] Zong, Y., Brown, S. W., Johnson, B. C., Lykke, K. R., and Ohno, Y. "Simple spectral stray light correction method for array spectroradiometers," Applied Optics 45, 1111 (2006). 